American Journal of Applied Sciences 6 (4): 656-660, 2009

ISSN 1546-9239

(C) 2009 Science Publications

\title{
Use of Satellite Data to Study the Impact of Land-Cover/Land-Use Change in Madison County Alabama
}

\author{
Tomas Ayala-Silva, Garry Gordon and Robert Heath \\ USDA, ARS, National Germplasm Repository \\ Subtropical Horticulture Research Station \\ 13601 Old Cutler Road, Miami, FL, USA 33158
}

\begin{abstract}
The monitoring of land/use land cover changes along the northern part of Madison County Alabama are essential for the developers, planners, policy makers and management of government, public and private organizations. Remote sensing was used to analyze and study land-use/land-cover use changes impact on the environment of Madison County Alabama. This study area was selected because it is one of the fastest growing areas in the state of Alabama. The study used data sets obtained from several sources. Remote sensing images, land-use/land-cover use maps, global positioning data. The remote sensing images were LANDSAT Thematic Mapper (TM) images acquired during April 1987 and May 1997. The data was processed and analyzed using MAP-X/RS and ERDAS. Six classes or categories of land-use/land-cover were analyzed to determine changes and the relationship to suburban sprawl. Each method used was assessed and checked in field. Six land use/land cover classes are produced. The overall accuracy for the 1987 image is $(78.92 \%)$ and for the 1997 image is $(85.44 \%)$ Analysis of the images for 1987 and 1997 showed a (26 and 15\%) increase in the urbanization and industrial development respectively and a decrease in all other classes. The most significant decrease $(25 \%)$ was in the pastures class, however, less significant changes were observed for the water resources and forest. The results from this study could be beneficial to state/county planners, researchers and policy makers.
\end{abstract}

Key words: Remote sensing, geospatial, LANDSAT, classification

\section{INTRODUCTION}

Land cover change plays an important role in regional, social and economic development and global environmental changes. It contributes significantly to Earth-atmosphere interactions and biodiversity loss is a major factor in sustainable development and human responses to global change and is important in integrated modeling and assessment of environmental issues in general. Land use/cover changes are also important fundamentals of the universal environmental change process ${ }^{[1]}$. Swift urban development in the world is somewhat alarming, especially, in industrialized countries like the United States. Urbanization (urban sprawl) is a process through which the productive agricultural lands, forests, surface water bodies and groundwater prospects are being irreversibly $\operatorname{lost}^{[2]}$.

Land cover scientists use satellite images and other remotely sensed imagery to assess national and global land cover characteristics and monitor how-and how rapidly-land cover changes. They also study the economic impacts of land cover change as well as its effects on water quality, the spread of invasive species, habitat and biodiversity loss, climate variability and other environmental factors. Scientists require up-todate land cover information to accurately understand current conditions and to assess the extent and impacts of land cover change on the Earth system ${ }^{[2]}$.

Multi-temporal satellite image composites are now of standard use in land cover classification of large areas at regional and global scales ${ }^{[3]}$. Scientists, researchers and planners have paid much attention to the issues of land cover change over the past decade $^{[4-16] \text {. }}$

Land Use and Land Cover (LULC) change is one of the most visible results of human modification of the terrestrial ecosystem and it has a significant impact on the local, regional and global environment ${ }^{[17]}$. Studies of the detailed history of LULC change in an area can

Corresponding Author: Tomas Ayala-Silva, USDA, ARS, National Germplasm Repository, Subtropical Horticulture Research Station, 13601 Old Cutler Road, Miami, FL, USA 33158 
help explain the spatial extent and the degree of the change itself and help to assess the directions and degree of other human-related environmental changes. The terms land use and land cover are often used simultaneously to describe maps that provide information about the types of features found on the earth surface (land cover) and the human activity that is associated with them (land use). In some cases, a hybrid approach results in both land cover and land use being mapped together. These maps are produced from remotely sensed data (satellite images and aerial photography) at scales that are amenable to planning, environmental assessment and development studies ${ }^{[5]}$. Information on the rates, driving forces and consequences of land use and land cover change is important in studies concerning issues ranging from the health of forests to global changes ${ }^{[4]}$. Changes occur at all levels and changes at local levels can have drastic effects at global levels. These changes should not be considered only at local levels, but also at state and national level. The main challenge faced by researchers and policy-makers is the lack of data and knowledge on the rates at which land-use/land-cover changes occur and their consequences.

This study used remote sensing to analyze and assess the effects of land-use/land-cover changes on Madison County Alabama. Remote sensing has been shown to be a cost effective way for the study of land use/land-cover change. In addition, provides coverage of areas of interest and provide excellent monitoring capabilities for the environment. The purpose of this study was to analyze land cover/land use changes between 1987 and 1997 for Madison county region, Alabama using LANDSAT Thematic Mapper (TM) data and to evaluate changes following an increase in residential and industrial areas.

\section{MATERIALS AND METHODS}

The study site: Madison County is located in northern Alabama. It is considered the third most populated county in Alabama and perhaps the most developed. Madison County (Fig. 1) is located at 034:44:00 latitude and 086:34:00 longitude in the heart of the Tennessee Valley. The county includes $\sim 2113 \mathrm{~km}^{2}$ ranging from the southernmost Appalachian Mountains to the Tennessee River. Two of the sites selected were near Interstate I-565, which serves as a differentiation point between urban/suburban and industrialized areas. The urban sites were Huntsville and Madison. The suburban/rural areas were, Hazel Green, Meridianville and Harvest.
Madison County was chosen because of its importance, both in advance technology and economics. Marshall Space Flight Center, US Army Missile and Space Command, Boeing, Northrop Grumman and other major government agencies and contractors are located in Madison County. Due to a demand for real state for businesses, industry, housing and other

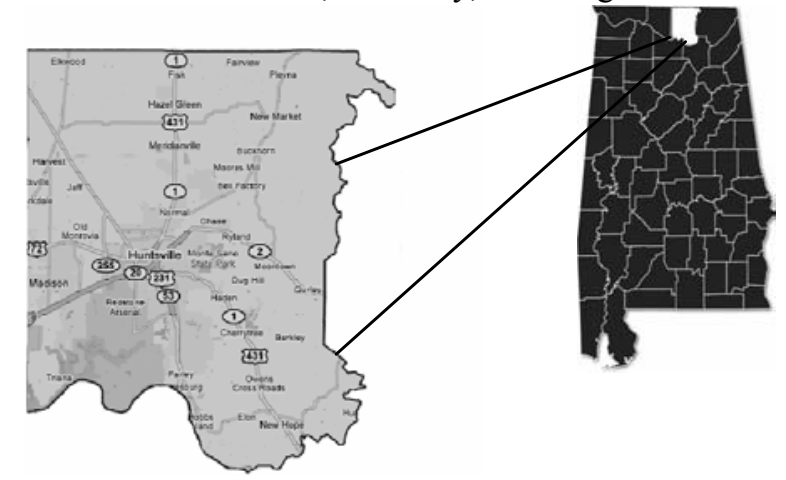

Fig. 1: Study area Madison county Alabama

facilities (schools, roads, industrial parks, etc.) Madison County has been under intensive development during the past decade. The issues taken under consideration were: agricultural land, vegetation, urban/rural development, water and wetlands.

Data: LANDSAT TM images with a spatial resolution of 30X30 meters were used to conduct this study. Two LANDSAT TM images of northern Alabama were used for this analysis, April 1987 and May 1997. The 1997 data were geometrically corrected to the Universal Transverse Mercator projection using a $30 \mathrm{~m}$ grid. Then, the 1987 image was registered to the 1997 geo coded image by scene to scene re-sampling. The images were imported, processed and analyzed using MAPX/RS and Geomatica 9.0. A stratified random sampling design was used in the analysis evaluation (17).

Thirteen classes or categories were used in this study: Agricultural, vegetation, water, urban, forest, suburban, industrial, pastures and wetlands. These categories provided less ambiguity in classifying the images. Five sites (towns) were selected for further analysis to determine if development (urban sprawl) promoted land use/land cover changes. To verify the accuracy of the classification ground truth of the areas was conducted. Comparison of the classification for the images (Fig. 2 and 3) were performed to determine the change over the period of April 1987 through May 1997. 
Supervise classification technique using maximum likelihood classifier was applied while preparing thematic urban land use map for 1987 and 1997. More than 40 training samples for each image were prepared for the classification. A minimum of 120 pixels were selected in the training areas for each class. Hundred random spatial points were generated for each thematic map for accuracy assessment.

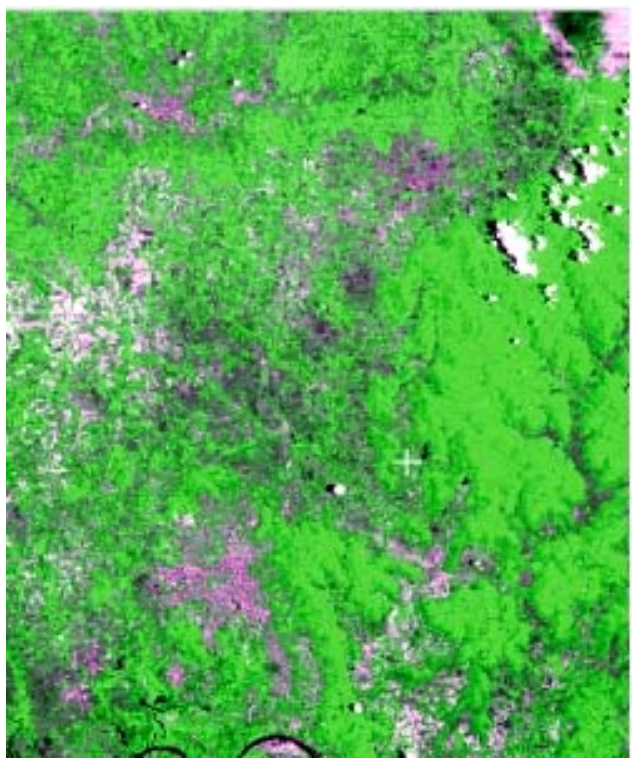

Fig. 2: Madison county, Alabama post classification image 1987

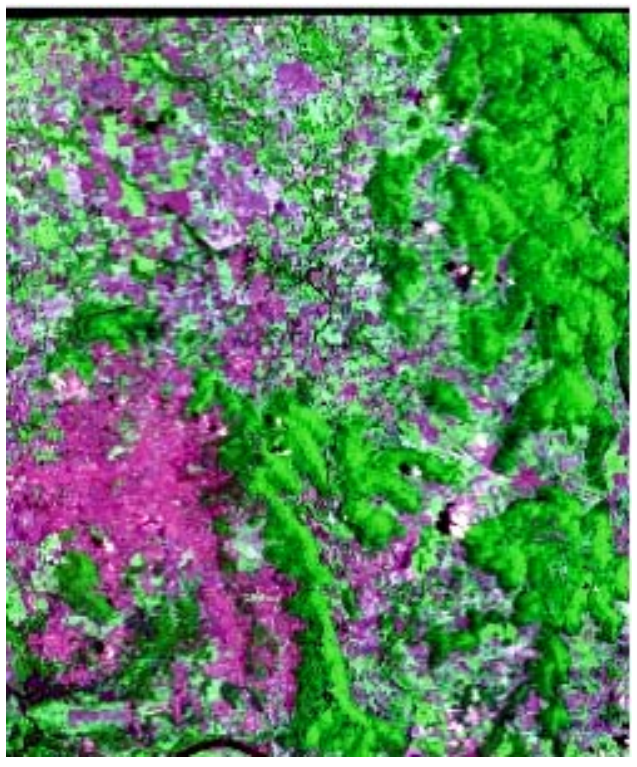

Fig. 3: Madison county Alabama post classification image 1997

\section{RESULTS AND DISCUSSION}

Natural resources utilization concerns and development techniques are very important, especially in areas with fast growing areas such as Huntsville, Alabama which is considered the leading economic growth centers in the Southeast. Therefore, remote sensing information such as that from satellite images is a great instrument for monitoring and adjusting information on such advances. For the 1987 image, 1020 pixels were indiscriminately selected and then checked against data on the ground. A stratified random sampling design ${ }^{[17]}$ was adopted in the analysis evaluation.

The overall accuracy of the classification procedure was estimated by calculating the percentage of the classified pixels (those pixels in the major diagonal of the matrix) from the total number of all classes. The results show an overall accuracy of $(78.92 \%)$ and a kappa index of 0.7475 (Table 1). Three classes shows poor results (producers accuracy) class 3, class 4 and class 9 . On the other hand, for the user accuracy, all but class 5, class 6 and class 13 were over $(70 \%)$. For the 1997 land use/land cover image, approximately 1000 pixels were chosen. These were checked with GPS at training locations. The results demonstrated an overall accuracy of $(85.40 \%)$ and a kappa index of 0.7932 (Table 2). In probing the producers precision, all classes but class 6 and class 8 were under $(70 \%)$ The accuracy assessment of the classification could be better attained if we have recent reference data (i.e. topographical maps, hydrology and transportation of the region).

A total of nine classes were produced from the images (Fig. 2 and 3). Two main classes have increased rapidly in Madison county Alabama. The residential class, which represents all residential homes, in rural and urban zones, has increased from $495 \mathrm{~km}^{2}$ in 1987 to $627 \mathrm{~km}^{2}$ in 1997 (Table 3). The industrial class has increased due to a heavy demand from industry, schools and universities and relocation of government agencies to Madison county.

Agricultural land, forests, vegetation, water and wetlands areas have decreased due to an increase in demand for real state land. Water and wetland loss could be attributed to new developments near lakes and rivers. The foremost decline was observed for the agriculture and pastures classes from $625 \mathrm{~km}^{2}$ in 1984 to $505 \mathrm{~km}^{2}$ in 1997 . This could be due to the increase in construction of buildings and houses. In addition, forests, other vegetation and wetlands, also decreased but at a lower rate (Table 3). These results are in agreement with previous US Census reports ${ }^{[18,19]}$.

The Huntsville-Madison area continues to undergo development in order to accommodate current and future land use. The main problem has been suburban/rural sprawl (industry, subdivisions, shopping centers, schools). This pattern is observed across all areas of the study, Huntsville and Madison are two major industrial centers with a very dynamic working 
Am. J. Appl. Sci., 6 (4): 656-660, 2009

Table 1: Classification precision evaluation for the 1987 image

\begin{tabular}{|c|c|c|c|c|c|c|c|c|c|c|c|c|c|c|c|}
\hline & \multicolumn{13}{|c|}{ Reference data } & \multirow{2}{*}{$\begin{array}{l}\text { Row } \\
\text { total }\end{array}$} & \multirow{2}{*}{$\begin{array}{l}\text { User } \\
\text { accuracy } \\
(\%)\end{array}$} \\
\hline & 1 & 2 & 3 & 4 & 5 & 6 & 7 & 8 & 9 & 10 & 11 & 12 & 13 & & \\
\hline 1 & 155 & 5 & & & & & & & & & & & & 160 & 96.87 \\
\hline 2 & & 258 & & 38 & & & & & 19 & & & & & 315 & 81.90 \\
\hline 3 & & & 94 & & 5 & 13 & & & & 3 & & & & 115 & 81.73 \\
\hline 4 & & & 8 & 62 & & 2 & & & 6 & 2 & & & & 80 & 77.50 \\
\hline 5 & & & 20 & & 55 & 4 & & & 1 & 1 & & & & 81 & 67.90 \\
\hline 6 & & & 52 & & & 58 & & & & 3 & 2 & & & 115 & 50.43 \\
\hline 7 & & & & & & 3 & 18 & & & & & 1 & 1 & 23 & 78.26 \\
\hline 8 & & & & & & 3 & 3 & 36 & & & 6 & & 1 & 49 & 73.46 \\
\hline 9 & & & 2 & & & & & & 16 & 1 & & 1 & & 20 & 80.00 \\
\hline 10 & & & & & & & & & & 22 & & & & 22 & 100.00 \\
\hline 11 & & & & & & 2 & & & & & 10 & & & 12 & 83.33 \\
\hline 12 & & & & & & 1 & & 1 & & 1 & & 16 & & 19 & 84.21 \\
\hline 13 & & & & & & & & 4 & & & & & 5 & 9 & 55.55 \\
\hline Column total & 115 & 263 & 176 & 100 & 60 & 86 & 21 & 41 & 42 & 33 & 18 & 18 & 7 & 1020 & \\
\hline Producer accuracy (\%) & 100.0 & 98.84 & 53.40 & 62.00 & 91.60 & 67.44 & 85.71 & 87.80 & 48.48 & 66.66 & 55.55 & 88.88 & 71.43 & & \\
\hline
\end{tabular}

Class $1=$ Background, Class 2 =Agriculture 1 , Class 3 =Forest, Class 4 =Vegetation, Class $5=$ Agriculture 2, Class $6=$ Water, Class 7 =Agriculture 3, Class $8=$ Industrial, Class $9=$ Forest 2, Class $10=$ Wetlands, Class $11=$ Pastures, Class $12=$ Urban (Residential), $13=$ Rural (Residential). Overall accuracy of (78.92\%) and a kappa index of 0.7475

Table 2: Classification precision evaluation for the 1997 image

\begin{tabular}{|c|c|c|c|c|c|c|c|c|c|c|c|c|c|c|c|}
\hline & \multicolumn{13}{|c|}{ Reference data } & \multirow{2}{*}{$\begin{array}{l}\text { Row } \\
\text { total }\end{array}$} & \multirow{2}{*}{$\begin{array}{l}\text { User } \\
\text { accuracy } \\
(\%)\end{array}$} \\
\hline & 1 & 2 & 3 & 4 & 5 & 6 & 7 & 8 & 9 & 10 & 11 & 12 & 13 & & \\
\hline 1 & 280 & & & & & & & & & 2 & & & & 282 & 99.29 \\
\hline 2 & & 220 & 12 & 6 & & & & & & & & & & 238 & 92.43 \\
\hline 3 & & & 65 & & 14 & & & & & & & & & 79 & 82.27 \\
\hline 4 & & 8 & 13 & 60 & & & & & & & & & & 81 & 74.07 \\
\hline 5 & & & 4 & & 98 & & & & & & & & & 102 & 96.00 \\
\hline 6 & & & & & 2 & 10 & & & & 3 & & & & 15 & 66.66 \\
\hline 7 & & & & 31 & & & 50 & & & & & & & 81 & 96.15 \\
\hline 8 & & & & & 8 & & & 16 & 4 & & & & 1 & 29 & 57.14 \\
\hline 9 & & & 5 & & & & & & 15 & & & & & 20 & 75.00 \\
\hline 10 & & & & 2 & & 2 & & & 1 & 14 & 1 & & & 20 & 70.00 \\
\hline 11 & & & 5 & & & & & & & 3 & 16 & & & 24 & 66.66 \\
\hline 12 & & & & & & & & 2 & & & & 14 & 2 & 18 & 77.77 \\
\hline 13 & & & & & & & & & & & & 5 & 6 & 11 & 100.00 \\
\hline Column total & 280 & 228 & 104 & 99 & 122 & 12 & 50 & 18 & 20 & 22 & 17 & 19 & 9 & 1000 & \\
\hline Producer accuracy (\%) & 100.00 & 96.49 & 62.25 & 60.60 & 80.32 & 83.33 & 100.00 & 88.88 & 75.00 & 70.00 & 70.00 & 73.68 & 66.66 & & \\
\hline
\end{tabular}

Table 3: Results of hybrid classification for 1987 and 1997 images showing area for each class $\left(\mathrm{km}^{2}\right)$, class percentage and area change $\left(\mathrm{km}^{2}\right)$

\begin{tabular}{lllll}
\hline $\begin{array}{l}\text { Classes/ } \\
\text { categories }\end{array}$ & $\begin{array}{l}\text { 1987 Land/ } \\
\text { use cover } \\
\text { area }\left(\mathrm{km}^{2}\right)\end{array}$ & $\begin{array}{l}\text { 1997 Land/ } \\
\text { use cover } \\
\left(\mathrm{area}^{2}\right)\end{array}$ & $\begin{array}{l}\text { Area } \\
\text { change } \\
\left(\mathrm{km}^{2}\right)\end{array}$ & $\begin{array}{l}\text { Total } \\
\text { change } \\
(\%)\end{array}$ \\
\hline $\begin{array}{l}\text { Urban/suburban } \\
\text { (residential) }\end{array}$ & 495 & 627.00 & 132.00 & +26.00 \\
Agriculture & 625 & 505.00 & 120.00 & -16.00 \\
Water & 21.0 & 20.00 & 0.66 & -4.76 \\
Wetlands & 83.5 & 76.55 & 6.95 & -8.00 \\
Forests & 681 & 640.00 & 41.00 & -7.00 \\
Industrial & 159 & 185.00 & 26.00 & 16.00 \\
Pastures & 265 & 195.00 & 70.00 & -25.00 \\
Vegetation & 100 & 85.00 & 15.00 & $-15 \%$ \\
\hline
\end{tabular}

population. All of these sites have been developing additional facilities (schools, churches, roads) to accommodate its working force, most at the expenses of natural resources (forests, agricultural land, rivers and lakes).

\section{CONCLUSION}

A post-classification technique was used in this investigation using a hybrid classification (unsupervised and supervised). This study demonstrated the utilization of remote sensing to assess the magnitude and distribution of LULC in an extensive area. Huntsville/Madison County and surrounding areas, like most large cities around the world are 
undergoing dramatic challenges more than ever before. As industrial activities and population of this county and other counties in Alabama continue to increase, so too will be an increased impact on the natural resources and local environment. It is therefore important that studies of this nature be conducted to determine the magnitude and distribution of LULC. Future studies may determine the causal relationship of suburban/rural sprawl and rate of LULC.

\section{REFERENCES}

1. Dewidar, M.K.H., 2002. Landfill detection in Hurghada, North Red Sea, Egypt, using thematic mapper images. Int. J. Rem. Sens., 23: 939-948.

2. Pathan, S.K., D. Sampat Kumar, M. Rao and S.V.C. Sastry, 1993. Urban growth trend analysis using GIS techniques. A case study of the Bombay metropolitan region. Int. J. Rem. Sens., 14: 3169-3179.

3. Chen, X.W., 2002. Using remote sensing and GIS to analyze land cover change and its impacts on regional sustainable development. Int. J. Rem. Sens., 23:107-124.

4. Ayala-Silva, T. and Y. Twumasi, 2004. Hurricane georges and vegetation change in puerto rico using AVHRR satellite data. Int. J. Rem. Sens., 25: 1629-1640.

5. Tucker, C.J., H.D. Dregne and W.W. Newcomb, 1991. Expansion and contraction of the Sahara desert from 1908-1990. Science, 253: 299-301.

6. Townshend, J.R.G., C.O. Justice, C. Gurney and J. McManus, 1992. The impact of misregistration on change detection. IEEE Trans. Geosci. Rem. Sens., 30: 1054-1060.

7. Lambin, E.F. and A.H. trahler, 1994. Indicators of land-cover change for change-vector analysis in multitemporal space at coarse spatial scales. Int. J. Rem. Sens., 15: 2099-2119.

8. Vitousek, P., 1994. Beyond global warming: Ecology and global change. Ecology, 75: 1861-1876.
9. Douglas, I., 1994. Human Settlements. In: Changes in Land Use and Land Cover: A Global Perspective, Meyer, W.B. and B.L. Turner (Eds.). ISBN 0521470854 Cambridge Press, Cambridge, UK, pp: 149-169.

10. Coppin, P.R. and M.E. Bauer, 1996. Digital change detection in forest ecosystems with remote sensing imagery. Rem. Sens. Rev., 13: 207-234.

12. Dai, X. and S. Khorram, 1997. Quantification of the impact of misregistration on the accuracy of remotely sensed change detection. In: Geoscience and Remote Sensing, 1997. IGARSS '97. Remote Sensing-A Scientific Vision for Sustainable Development, Singapore, 3-8 August 1997I. EEE International, pp: 1763-1765. Piscataway, N.J.

13. Lambin, E.F., 1997. Modeling and monitoring land-cover change processes in tropical regions. Phys. Geo., 21: 375-393.

14. Foody, G.M. and D.S. Boyd, 1999. Detection of partial land cover change associated with the migration of inter-class transitional zones. Int. J. Rem. Sens., 14: 2723-2740.

15. Stow, D., 1999. Reducing misregistration effects for pixel-level analysis of land-cover change. Int. J. Rem. Sens. 20: 2477-2483.

16. Stow, D.A. and D.M. Chen, 2002. Sensitivity of multitemporal NOAA AVHRR data of an urbanizing region to land-use/land-cover changes and misregistration. Rem. Sens. Environ., 80: 297-307.

17. Weng, 2002. Land use change analysis in the zhujiang delta of China using satellite remote sensing, GIS and stochastic modeling. J. Environ. Manage., 64: 273-284.

18. Lehtonen, R. and E. Pahkinen, 2004. Practical Methods for Design and Analysis of Complex Surveys. 2nd Edn. Wiley Publishing Inc., Hoboken, New Jersey, pp: 360. ISBN: 9780470091630

19. http://www.usda.gov/nass/pubs/trends/references. 